\title{
Feeding Migration of Short-finned Squid Illex argentinus in the Waters off Argentina ${ }^{* 1}$
}

\author{
Hiroshi Hatanaka*2 \\ (Received February 1, 1987)
}

\begin{abstract}
The migration pattern of Illex argentinus in the waters off Argentina was estimated based on the data collected by research survey from April 1978 to April 1979 and on fisheries statistics of Japanese commercial vessels. In spring of the Southern Hemisphere juvenile squid appear in the northern half of the Patagonian Shelf excluding the area covered by the coastal waters. They disperse gradually towards offshore and southern waters, and spread their habitat to almost the entire shelf by summer. In autumn they move towards the east (the edge of the shelf) and north, and aggregate on the slope of $400-700 \mathrm{~m}$ in depth for some time in the north and middle parts of the shelf. Then they leave the slope probably for spawning in winter.
\end{abstract}

Calamar Illex argentinus (Castellanos), a species of short-finned squids, is distributed in the waters off Argentina and Uruguay. The substantial fishery for this squid started in waters off Argentina in 1978. Since then, fishing vessels from Argentina, German Democratic Republic, Japan, Korea, Poland, Taiwan, Uruguay and U.S.S.R. have been engaged in the exploitation of this species. The annual catches in recent years have reached 200,000 tons. However, the information on the biology and population dynamics of this species is still insufficient, ${ }^{1)}$ and no detailed analysis on the migration has been reported.

A joint survey between Japan and Argentina for the purpose of estimating standing stock sizes of bottom fishes was carried out in the waters off Argentina using a trawler, the R/V Shinkai Maru, from April 1978 to April 1979. A large amount of data on bottom fishes including calamar was collected from the survey. The preliminary result obtained with the cooperations of scientists of two countries was already reported. ${ }^{2)}$ The growth and life span of calamar were estimated based mainly on monthly size composition data collected during the survey. ${ }^{32}$ The present paper analyzes the migration of this species in a period inhabiting the continental shelf and slope based on catch data at the trawl stations arrayed into a grid in the survey and on Japanese fisheries statistics in this area.

The author wishes to express his sincere thanks to Prof. T. Okutani, Tokyo University of Fisheries, and to Drs. H. Otaki and S. Ohsumi, Far Seas Fisheries Research Laboratory, for critical review and valuable advises on the manuscript. He also express his hearty thanks to the staff of Japan Marine Fishery Resource Research Center, who collected the data during the survey.

\section{Materials and Methods}

Data from two sources were used in this paper. They were the data from Japan/Argentina joint trawl survey by the R/V Shinkai Maru $(3,393$ GRT) and fisheries statistics on Japanese trawl and squid-jig fisheries in the Southwest Atlantic.

As the main purpose of the joint survey was to estimate standing stock sizes of several fishery resources, a grid survey method by means of bottom trawl gear was applied to most of the cruises. In principle, a 30-minute tow was made at each trawl station which was arrayed into $1^{\circ} \times 1^{\circ}$ grid. The survey was conducted during 13 months from April 1978 to April 1979, covering the Patagonian Shelf and the slope shallower than $1,000 \mathrm{~m}$ in depth between $35^{\circ} \mathrm{S}$ and $55^{\circ} \mathrm{S}$ latitudes (Fig. 1). Details of the survey including gears used were described in the survey report. ${ }^{2}$ In the present paper, the catch of calamar per unit of area swept (tons/n. mile ${ }^{2}$ ) at each trawl station was used as a relative density of this species for estimating the seasonal change of habitat.

The fisheries statistics*3 have been collected by the Far Seas Fisheries Research Laboratory for

*1 Contribution from Far Seas Fisheries Research Laboratory, No. 253.

*2 Far Seas Fisheries Research Laboratory, Shimizu 424, Japan (烟中 寛：遠洋水産研究所).

*3 Those statistics are not published but filed in Far Seas Fisheries Research Laboratory. 


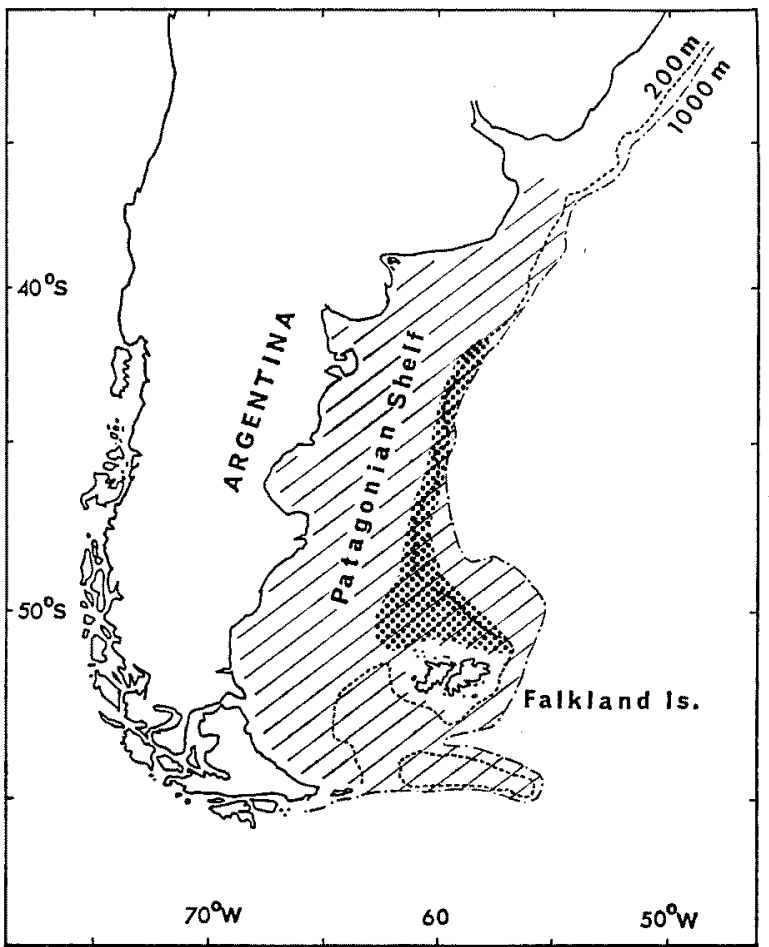

Fig. 1. Map showing the area surveyed by the R/V Shinkai Maru, April 1978-April 1979 (oblique lined) and fishing grounds of Japanese vessels (dotted).

high-sea trawl fishery since 1978 and for squid-jig fishery since 1985. In this report, monthly CPUEs of both trawlers and jiggers and the towing depths of several trawlers recorded in their logbooks were used for detecting the movement of calamar.

Since this species has a life span of one year and is born in July-September, ${ }^{3}$ ) two successive year classes were handled during the joint survey, viz. 1977 year class from April 1978 to August 1978 and 1978 year class from September 1978 to April 1979. In this paper, analyses were made in the order of growth regardless of year classes, assuming no substantial differences in migration pattern will exist between year classes.

\section{Results}

The smallest size group observed throughout cruises of the R/V Shinkai Maru had a length mode at about $5 \mathrm{~cm}$ in mantle length (ML), and appeared at six trawl stations in the period of 21 September-12 October 1978 (the 6th cruise), as shown in Fig. 2. This period corresponds to the last stage of spawning season, and some large matured animals were also caught at not a few of the stations. For simplification, data relevant to them are excluded in Fig. 2 (see Hatanaka) for details of size composition). The smallest size group appeared in the frontal zone between warmer coastal waters and cooler offshore waters (Falkland/Malvinus Current).

The results in the period of 19 October-14 November 1978 (the 7th cruise) are also shown in Fig. 2. Although some large animals (the previous year class which is not incorpolated in the figure) still remained, young animals having a mode at about $14 \mathrm{~cm}$ ML appeared mainly in the frontal zone and its slightly offshore side in the northern half of Patagonian Shelf.

In the period of 12 January-14 March 1979 (the 10th and 11th cruises), squid were distributed almost all over the shelf excluding the area covered by warmer coastal waters (Fig. 3). The density of squid was fairly uniform but more or less higher in the middle and southern parts of the shelf. Although the area covered in the period of 19 March-11 April 1979 (the 12th cruise) was limited, the distribution pattern was similar to that in the former period (Fig. 3). 

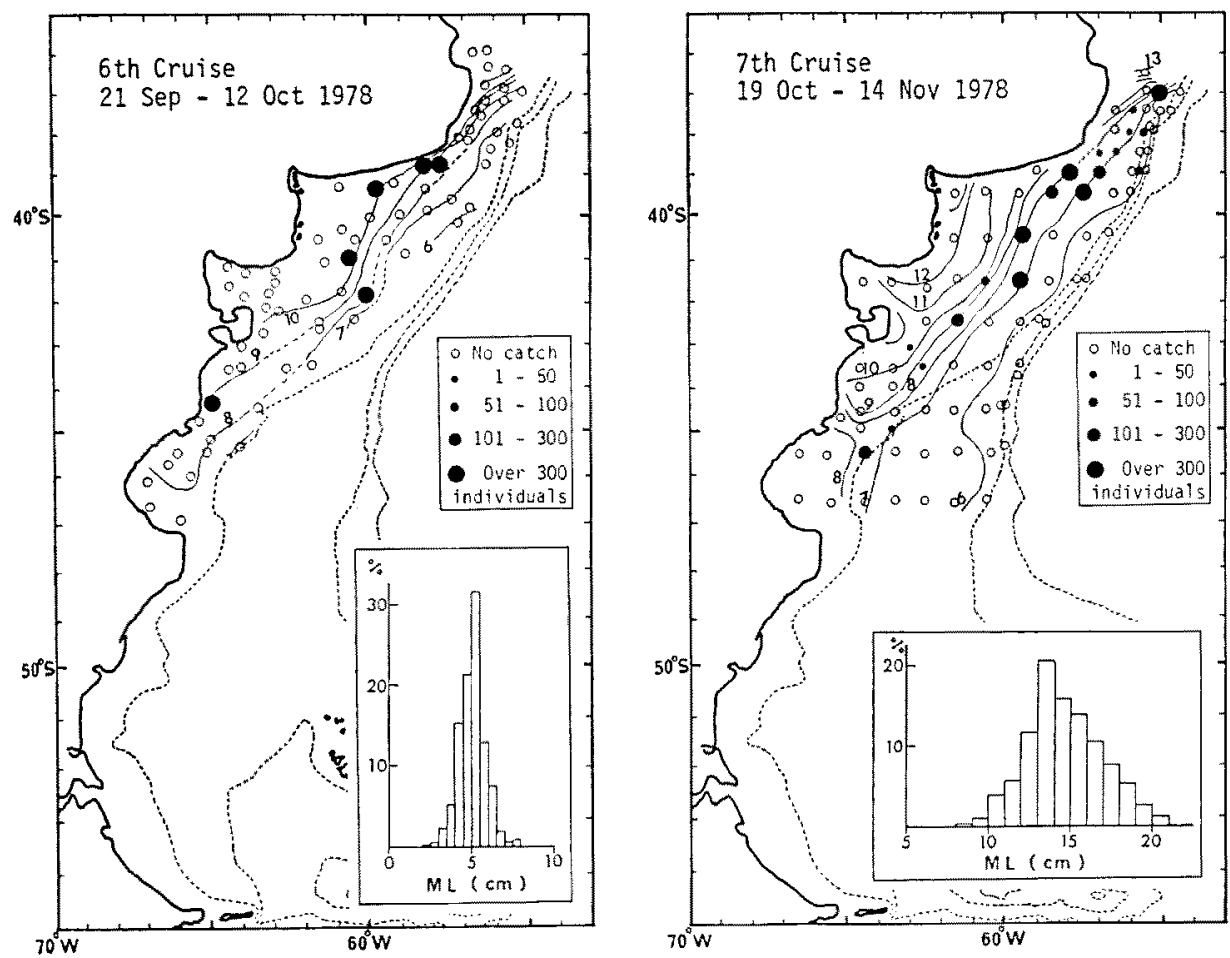

Fig. 2. Trawl stations where juvenile and young squid caught in the 6 th and 7 th cruises of the R/V Shinkai Maru, with the length compositions of catch. Solid line s are isotherms of bottom layer $\left({ }^{\circ} \mathrm{C}\right)$ and dotted lines are depth contours of 100,200 and $1000 \mathrm{~m}$.
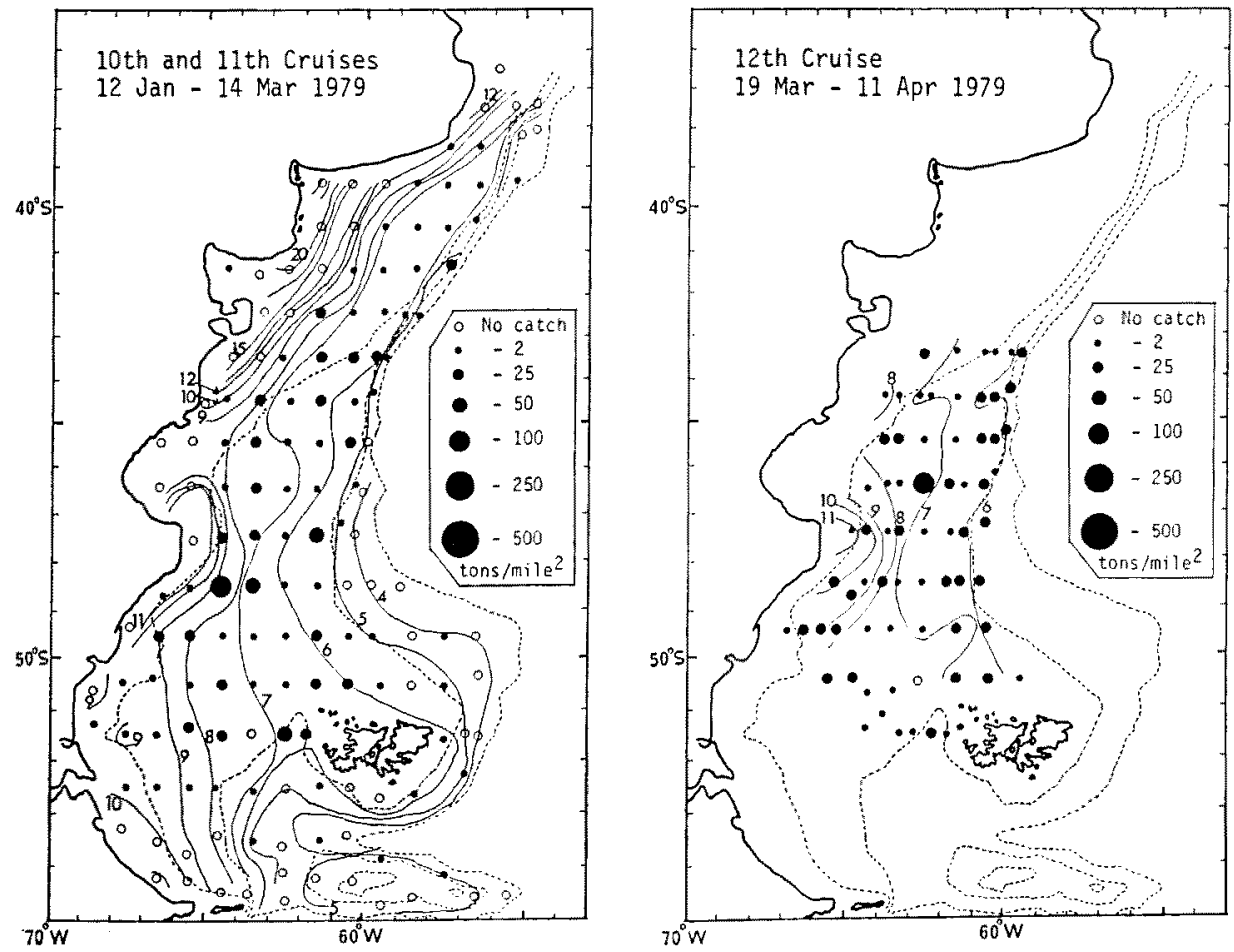

Fig. 3. Squid catch per unit of area swept in the 10-11th and 12th cruises of the R/V Shinkai Maru. For legend, see Fig. 2. 

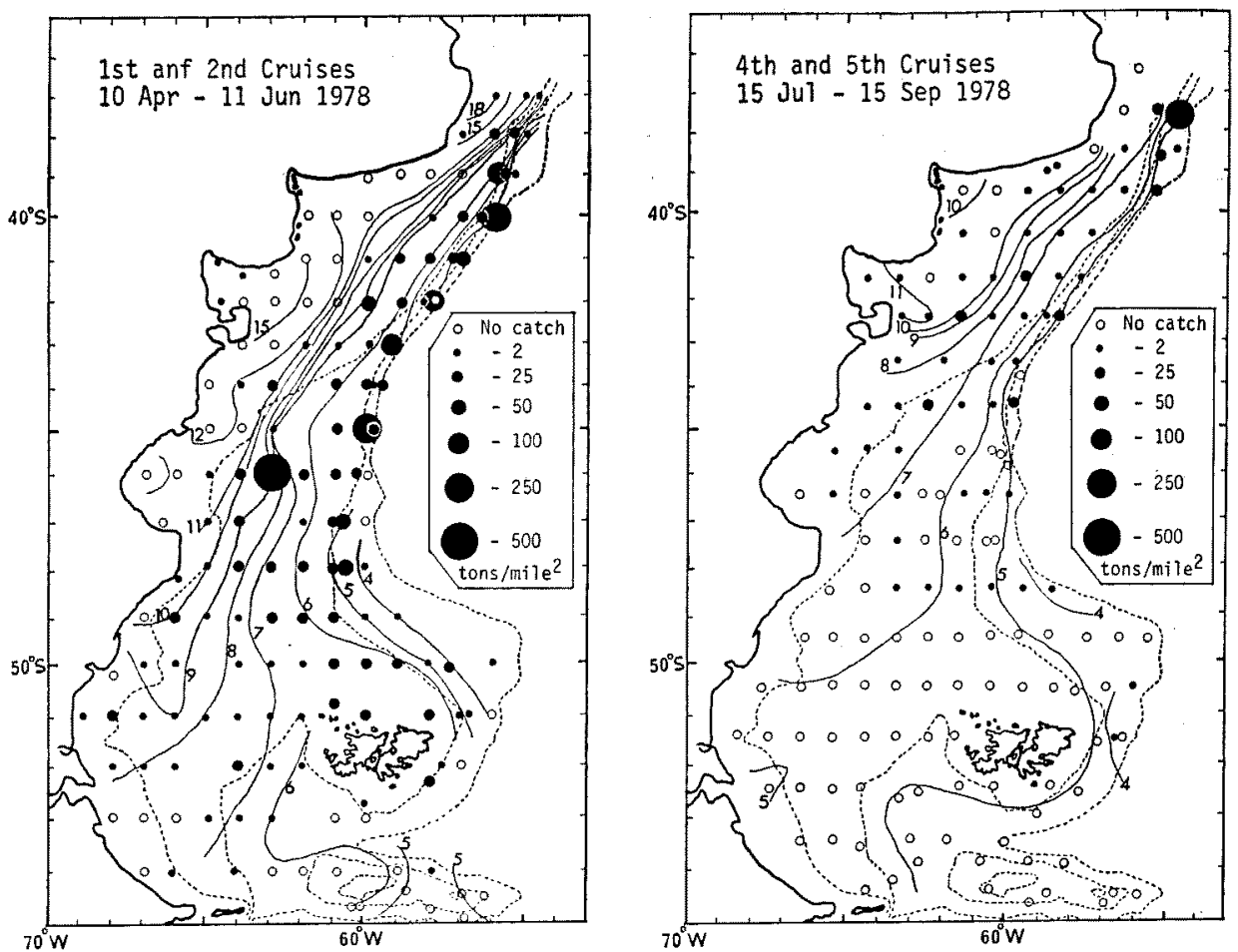

Fig. 4. Squid catch per unit of area swept in the 1st-2nd and 4-5th cruises of the R/V Shinkai Maru. For legend, see Fig. 2.
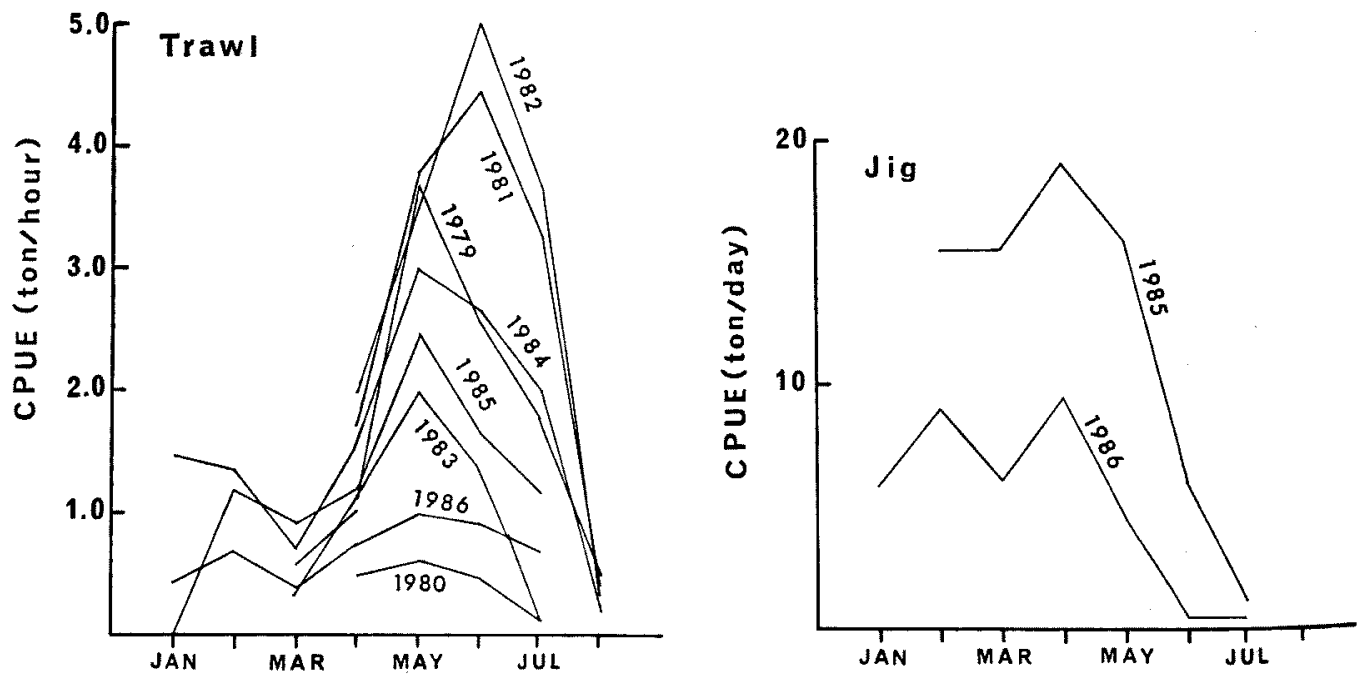

Fig. 5. Monthly changes in CPUEs of squid-directed fishery by Japanese trawlers (1500-3000 GRT) and by jiggers (250-500 GRT) in the waters off Argentina.

In the period of 10 April-11 June 1978 (the 1st and 2 nd cruises), squid were still distributed over the shelf excluding the coastal area, but they were abundant exclusively on the outer edge and slope in the northern and central parts of the shelf (Fig. 4). 

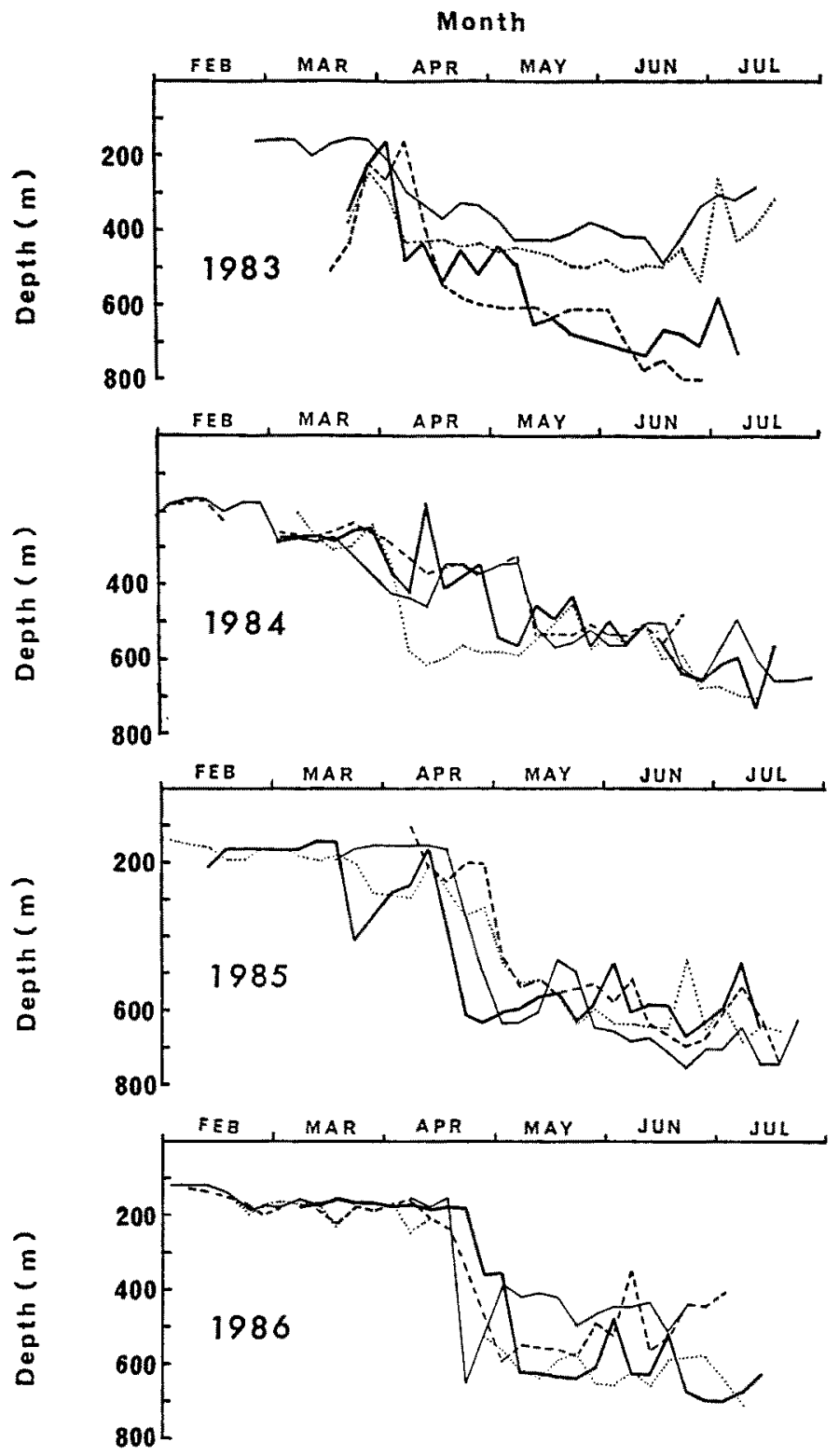

Fig. 6. Monthly changes in towing depths of several Japanese trawlers engaged in squid fishery. Average depths in every five days are shown in the figure.

The period of 15 July-15 September 1978 (the 4th and 5th cruises) corresponds to the spawning season. The abundance of the squid remarkably declined not only on the shelf but also on the slope, except a single station in the northern end of survey area (Fig. 4). No squid was found in the southern part of the shelf.

The results obtained by those cruises are summarized as follows;
1) In early spring (September and October) in the Southern Hemisphere, juveniles appeared in the frontal zone between warmer coastal waters and cooler offshore waters in the northern half of the Patagonian Shelf.

2) Then they gradually dispersed towards offshore and southern waters. By the time they attained to six months old in summer (January), they already spread their habitat over the whole 
Patagonian Shelf excluding coastal area.

3) In autumn (April and May), they moved towards the east (the edge of the shelf) and north, and aggregated on the slope in the north and middle parts of the shelf.

4) They left the slope in winter (July) for spawning.

The fishing grounds of both Japanese squid jiggers and trawlers are located on the outer edge and slope extruding outside of $200-\mathrm{n}$. mile zone of Argentina and north and northwest of the Falkland Is. (Fig. 1). Monthly squid CPUEs by jig fishery and those by trawl fishery in these fishing grounds are shown in Fig. 5. In the case of jig fishery, CPUEs were fairly high from January to March, highest in April, and then rapidly declined in June. CPUEs of trawl fishery were low from January till March or April, then rapidly increased in May, and dropped in July or August.

Average towing depth of some trawlers for every five days in several years are shown in Fig. 6. The towing depth changed drastically within the fishing season. The depth increased from April or May and attained to $500-700 \mathrm{~m}$ at the end of fishing season in July.

Those results were interpreted as follows;

1) The squid were widely distributed on the shelf in February and March, and jiggers caught them efficiently by means of fishing light at night. However, trawlers' CPUEs were low because of no way for attracting them in those months.

2) In April squid moved to outer edge of the shelf, and consequently CPUEs of jigger rose there.

3) In May and June the majority of the animals moved further to the slope and resulted in dense concentration in depths of $400-700 \mathrm{~m}$. Trawlers had good catches, but jiggers could not catch them any longer.

4) Most of the squid left the slope in July and the trawlers' CPUE dropped consequently

\section{Discussion}

It is well known that some squid species of Ommastrephid family migrate from the place where they are hatched to areas which allow them to feed sufficiently. They grow up and mature to some degree there till leaving for the spawning ground..$^{4,5)}$ Such a type of migration is generally called a feeding migration. It can be said that the movement traced in this paper corresponds to the feeding migration.

The direct evidence, such as from tagging experiment, was not available for this study. However, the migration pattern deduced from the survey data coincided well with characteristics of commercial fisheries. This fact indicates the reliableness of the results obtained in this study.

It should be taken into consideration that the survey data concerned only the squid in bottom layer as they were caught by bottom trawling. Especially juveniles might be distributed in surface and middle layers rather than bottom layer. Some of them were caught by bottom trawling mainly in the waters of $7^{\circ}-10^{\circ} \mathrm{C}$ in spring of the Southern Hemisphere, and the waters of such temperature in surface layer were located above the continental slope and its vicinity. Disregarding the water depth, juveniles and youngs seem to be widely distributed in the northern half of Patagonian Shelf excluding the area covered by the coastal waters.

More than one size group occurred especially in September and October during the survey. It is known that there is a minor group having well matured gonad in summer in addition to the major winter spawning group. ${ }^{3)}$ As apparent abundance of the major group was extremely low in September and October due to the fact that body size was too small for trawl gear in those months, minor group having larger body became contrarily prominent. In this paper only the major group was extracted and traced.

The reason why squid schools gather on the slope just before leaving the shelf has not been explained, but a similar phenomenon was observed in the Northwest Atlantic short-finned squid Illex illecebrosus. ${ }^{*}$ A research vessel caught a considerable amount of squid on the slope $(200-800 \mathrm{~m}$ deep) of the Scotian Shelf in October and November. These months were the season of emigration of the animals to the southern spawning ground, though the density was not so high as to be accessible for the commercial fishery.

There is no information on the movement and spawning ground of calamar after leaving the slope. Only a working hypothesis ${ }^{\text {i) }}$ suggests that the spawning may occur somewhere further north in the Brazilian Current and planktonic juveniles

* T. Amaratunga, M. Roberge, J. Young and Y. Uozumi: Summary of joint Canada/Japan research program on short-finned squid Illex illecebrosus, 23 Oct. to 29 Nov. 1979. NAFO SCR Doc. 80/11/40, Dartmouth, 1980, pp. 1-20. 
will be translocated by the current to the south.

\section{References}

1) J. Csirke: FAO Fish. Tech. Pap., No. 286, 1-75 (1987).

2) JAMARC: Fisheries survey report in the Argentine waters by $R / V$ SHINKAI MARU. JAMARC, Tokyo, 1980, pp. 1-193 (limited distribution).

3) H. Hatanaka: Nippon Suisan Gakkaishi, 52, 11-
17 (1986).

4) R. K. O'Dor: in "Cephalopod life cycle" (ed. by P. R. Boyle), Vol. 1, Academic Press, London, 1983, pp. 175-199.

5) T. Okutani: in "Cephalopod life cycle" (ed. by P. R. Boyle), Vol. 1, Academic Press, London, 1983, pp. 201-214.

6) H. Hatanaka, S. Kawahara, Y. Uozumi, and $S$. Kasahara: NAFO Sci. Coun. Studies, 9, 59-68 (1985). 